\title{
Nocturnal Enuresis Is Associated with Attention Deficit Hyperactivity Disorder and Conduct Problems
}

\author{
Subin Park, Bung-Nyun Kim $\bowtie$, Jae-Won Kim, Soon-Beom Hong, \\ Min-Sup Shin, Hee Jeong Yoo and Soo-Churl Cho \\ Division of Child and Adolescent Psychiatry, Department of Psychiatry, Seoul National University College of Medicine, Seoul, Republic of Korea
}

\begin{abstract}
Objective There are no published prevalence estimates of elimination disorders and their association with disruptive-behavior disorders among children in the Asian region using standardized diagnostic interviews. This study was conducted to determine the prevalence of elimination disorders and its association with disruptive-behavior disorders in a representative sample of children in Seoul, Korea.

Methods The diagnosis of enuresis and encopresis was derived from parent-reported data for "enuresis and encopresis," collected using the Diagnostic Interview Schedule for Children, from a representative sample of 6- to 12-year-old children $(\mathrm{n}=1,645)$ who participated in the 2005 Seoul Child and Adolescent Mental Health Survey. Prevalence data for attention deficit and disruptive-behavior disorders were collected from the same sample.

Results The overall 12-month prevalence of nocturnal enuresis and encopresis was $1.8 \%$ and $0.6 \%$, respectively. Enuresis and encopresis prevalence in boys was significantly greater than that in girls. Enuresis and encopresis was most common at 7 to 9 years of age. Enuresis was significantly associated with ADHD (OR 2.6, 95\% CI 1.0-6.9) and conduct disorder (CD; OR 4.7, 95\% CI 1.0-22.4).

Conclusion Enuresis is significantly associated with $\mathrm{ADHD}$ and $\mathrm{CD}$, so these conditions must be assessed together during the evaluation of children with enuresis.

Psychiatry Investig 2013;10:253-258
\end{abstract}

Key Words Enuresis, Encopresis, Prevalence, Comorbidities, ADHD, Conduct disorder.

\section{INTRODUCTION}

Elimination disorder consists of enuresis and encopresis. Both conditions are very distressful to children and their family members. Enuresis involves repeated voiding of urine onto clothes or bedclothes that persists beyond the normative age of maturation of urinary control. Encopresis is involuntary fecal soiling in children who have already been toilet trained. The prevalence estimates of enuresis ${ }^{1-16}$ and encopresis ${ }^{15,17-19}$ are highly variable, with a range of $3.8 \%{ }^{3}$ to $24 \%{ }^{6}$ for enuresis and $0.1 \%{ }^{15}$ to $3 \%{ }^{19}$ for encopresis.

The disparate estimates can be accounted for primarily by

Received: September 14, 2012 Revised: February 10, 2013

Accepted: February 20, 2013 Available online: September 16, 2013

$\triangle$ Correspondence: Bung-Nyun Kim, MD, PhD

Division of Child and Adolescent Psychiatry, Department of Psychiatry, Seoul

National University College of Medicine, 101 Daehak-ro, Jongno-gu, Seoul

110-744, Republic of Korea

Tel: +82-2-2072-3647, Fax: +82-2-747-5774, E-mail: kbn1@snu.ac.kr

(a) This is an Open Access article distributed under the terms of the Creative Commons Attribution Non-Commercial License (http://creativecommons.org/licenses/by$\mathrm{nc} / 3.0$ ) which permits unrestricted non-commercial use, distribution, and reproduction in any medium, provided the original work is properly cited. differences in enuresis definitions found in the International Classification of Diseases and Related Health Problems-10th Edition (ICD-10), ${ }^{20}$ the Diagnostic and Statistical Manual of Mental Disorders, 3rd Edition (DSM-III), ${ }^{21}$ the Diagnostic and Statistical Manual of Mental Disorders, 4th Edition (DSM-IV) ${ }^{22}$ and the International Children's Continence Society (ICCS). ${ }^{23}$ The DSM-III and ICD-10 require a bed-wetting frequency of twice per month in the past 3 months for children ages 5 and 6 years, and once per month in the past 3 months for children ages 7 years or older; the DSM-IV requires a bed-wetting frequency of twice per week for 3 consecutive months or the presence of clinically significant distress or impairment, irrespective of the age of the child. According to the ICSS, enuresis or (intermittent) nocturnal incontinence is defined as at least one wet night per month. Higher rates of enuresis were observed in population-based epidemiological studies that applied the less stringent DSM-III criteria, ${ }^{4,5}$ ICD-10 criteria, ${ }^{12,15}$ or ICSS definition. ${ }^{6,13}$ In addition to different diagnostic criteria, differences in the age range and ethnicity of children and cultural differences may also explain the varying prevalence estimates of enuresis across different 
studies.

Until now, there have been few enuresis and encopresis prevalence studies based on DSM-IV criteria. Two US studies yielded a prevalence rate of $3.8 \%{ }^{16}$ and $4.5 \%{ }^{10}$ for DSM-IV-defined enuresis. In Asian countries, there are no enuresis and encopresis prevalence studies using structured clinical interviews or formal DSM-IV diagnostic criteria, although there are a few prevalence studies using parental questionnaires for enuresis. $^{8,9,12,13,24}$

Previous studies have demonstrated a significantly increased prevalence of ADHD in children with enuresis. ${ }^{4,9,10,25-27}$ The comorbid ADHD rate of children with enuresis in a primary or secondary care setting was $10.3 \%$, and those in a specialized tertiary care setting was $28.3 \%{ }^{25}$ This high co-occurrence of enuresis and $\mathrm{ADHD}$ could be due to a common neurobiological pathology underlying these two conditions (e.g., delays in central nervous system maturation), ${ }^{28}$ common environmental factors (e.g., parental attitudes about toilet training and discipline), ${ }^{9}$ or casual relations in which bed-wetting-related psychosocial stress increases the risk for behavioral problems such as ADHD. ${ }^{29}$ The last two hypotheses suggest that other disruptive-behavior disorders (DBDs), such as oppositional defiant disorder (ODD) and conduct disorder (CD), also might be increased in children with enuresis. We are unaware of any studies examining the association between enuresis and ODD/CD or ADHD using structured diagnostic criteria, although there are a few studies using parental questionnaires for children's psychological problems..$^{30,31}$

This study was conducted to investigate the prevalence of elimination disorders and its association with ADHD and other disruptive-behavior disorders in a representative survey of children in Seoul, the capital city of South Korea, using the Diagnostic Interview Schedule for Children, version 4 (DISC-IV). ${ }^{32}$

\section{METHODS}

\section{Participants}

This study was part of the 2005 Seoul Child and Adolescent Mental Health Survey. ${ }^{33}$ Seoul is the capital of South Korea and the largest and most populous city in the country, with 0.7 million school-aged children. One-fourth of the inhabitants of Korea live in Seoul, and the inhabitants of Seoul vary according to social and economic status. In this survey, Seoul was divided into six school districts based on social and economic status. One elementary school was randomly selected from each school district, and 10 classes were randomly selected from each school. From 2,493 eligible children, parents of 1,645 students completed the DISC-IV ${ }^{32}$ (total response rate $=66.0 \%$ ). There were no significant differences between the samples of this study and the whole population of Seoul regarding age $(\mathrm{t}=0.26, \mathrm{df}=1, \mathrm{p}=0.796)$ or gender $\left(\chi^{2}=0.01, \mathrm{df}=1, \mathrm{p}=0.920\right)$. No significant demographic differences were found between responders and non-responders (age, $\mathrm{t}=0.48, \mathrm{df}=1, \mathrm{p}=0.717$; gender, $\mathrm{v} 2=0.02, \mathrm{df}=1, \mathrm{p}=0.888$ ). The survey was performed from September to December 2005. All six selected schools agreed to participate in the study, and the Institutional Review Board of the Seoul National University Hospital and the Seoul School Health Promotion Center approved this study. The teachers had sent letters to the parents indicating the objective of the study, a guarantee of confidentiality, and a contact telephone number and an email address of the principal investigator for any questions and concerns. Parents who accept to participate were invited to the school and contacted with interviewers. The interviewers were educated lay volunteers, all of whom previously been educated in the practice of the DISC-IV by skilled psychiatrists, and had received constant quality control monitoring by psychiatrists from the Department of Child and Adolescent Psychiatry at the Seoul National University Hospital. Written informed consent was obtained from parents before each interview. The child's biological mother was the informant in $94.9 \%$ of the cases.

\section{Measures}

Psychiatric disorders according to the DSM-IV were assessed using the Korean version of the DISC-IV. Interviews were organized into six diagnostic sections: anxiety disorders, mood disorders, disruptive-behavior disorders, substance-use disorders, schizophrenia, and miscellaneous disorders (eating, elimination and tic disorders, pica, and trichotillomania). The DISC-IV addresses six domains in which impairment might be present: 1) getting along with parents/caretakers; 2) participating in family activities; 3 ) participating in peer activities; 4) academic/occupational functioning; 5) relationships with teachers/bosses; and 6) distress attributable to symptoms. The severity of each domain was evaluated as mild, intermediate or severe. Among the six domains, the cases that showed at least two intermediate or at least one severe impairments were defined as impaired. In this study, the DISC-IV scoring algorithms were derived based on data from parents for ascertaining the presence of a diagnosis. The reliability and validity of the Korean version of the DISC-IV were previously determined. ${ }^{32}$

\section{Definitions of enuresis and encopresis}

The DISC-IV elimination disorders module collected information on the symptoms, frequency, age of onset, and impairment associated with nocturnal enuresis, diurnal enuresis, and encopresis within the past 30 days, the past 12 months, and lifetime. This study focused on the 12-month prevalence 
of enuresis and encopresis. To acquire a diagnosis of enuresis in this study, the child had to fulfill the following criteria: repeated voiding of urine onto bed or clothes, whether involuntary or intentional; the behavior was deemed clinically significant as manifested by either a frequency of twice per week for at least 3 consecutive months or the presence of clinically significant distress or impairment in social, academic, or other important areas of functioning; chronological age was at least 5 years; and the behavior was not due exclusively to the direct physiological effect of a substance (e.g., a diuretic) or a general medical condition (e.g., diabetes, spina bifida, a seizure disorder). To acquire an encopresis diagnosis in this study, the child had to fulfill the following criteria: repeated passage of feces onto inappropriate places (e.g., clothing or floor), whether involuntary or intentional; at least one such event a month for at least 3 months; chronological age of at least 4 years; and the behavior not exclusively due to the direct physiological effect of a substance (e.g., laxatives) or a general medical condition, except through a mechanism involving constipation.

\section{Definitions of full syndrome and subthreshold DBDs}

For the diagnostic assessment of DBDs, we assessed both full syndrome DBDs (all DSM-IV criteria met) and subthreshold DBDs. We made subthreshold diagnoses by including subthreshold symptoms that caused functional impairment but did not reach the DSM-IV threshold level (at least six of the nine inattentive and/or hyperactive/impulsive symptoms, four of the eight oppositional defiant behaviors, and three of the 15 conduct behavors). Any DBDs included both full syndrome DBD and subthreshold DBD.

Specifically, subthreshold ADHD was operationally defined as the presence of at least three, but not more than five, inattentive and/or hyperactive/impulsive symptoms, provided some impairment from the symptoms was present in two or more settings. A child must have also met the DSM-IV ADHD age-of-onset and impairment criteria to be diagnosed with subthreshold ADHD. Subthreshold ODD was operationally defined as the presence of two or three oppositional defiant behaviors that resulted in clinically significant functional impairment. A child must also have met the DSM-IV ODD exclusion criteria for a psychotic, mood, or conduct disorder to be diagnosed with subthreshold ODD. Subthreshold CD was operationally defined as the presence of two conduct behaviors that resulted in clinically significant functional impairment.

We used these subthreshold diagnoses for two reasons. First, we wanted to determine whether comorbidity with enuresis was increased only in clinical-level DBDs or also in less severe subthreshold DBDs. Second, the CD prevalence rates that met all DSM-IV criteria were expected to be too low to obtain adequate statistical power in these ages.

\section{Statistical analysis}

Descriptive statistics on the 12-month prevalence of enuresis are given for the sample overall and across demographic groups. Logistic regression was performed to assess the association of demographic factors with enuresis, encopresis, and elimination disorders. To investigate the association between enuresis and DBDs, the ORs and $95 \%$ confidence intervals were derived from a second set of logistic regression models using the presence of $\mathrm{ADHD}, \mathrm{ODD}$, and $\mathrm{CD}$ as the main outcome variables and the presence of enuresis as the principal predictor, after adjustment for sex, age, and family income. CBCL scores were compared between children with and without enuresis using an independent t-test. All statistical analyses were performed using SPSS (version 19.0; SPSS, Inc., Chicago, IL, USA), with statistical significance defined as an alpha level $<0.05$.

\section{RESULTS}

The prevalence of enuresis among the 1,645 children administered the complete DISC-IV in the 2005 Seoul Child and Adolescent Mental Health Survey is displayed in Table 1. The overall 12-month prevalence of any elimination disorder was $2.2 \%(1.5-3.0 \%)$. The prevalence of enuresis and encopresis was $1.8 \%(1.1-2.4 \%)$ and $0.6 \%(0.2-1.0 \%)$, respectively. There were no children with DSM-IV-defined diurnal enuresis; therefore, the term "enuresis" in this study is synonymous with "nocturnal enuresis". The prevalence of enuresis and encopresis in boys was significantly greater than that in girls (OR 2.4, 95\% CI 1.0-5. 5 and OR 8.2, 95\% CI 1.0-65.0, respectively). Enuresis and encopresis were most common in children 7 to 9 years of age. Children 7 years of age and children 9 years of age were significantly more likely to be diagnosed with enuresis compared with those 11 or 12 years old (OR 12.2, 95\% CI 1.6-100.2 and OR 11.2, 95\% CI 1.4-90.8, respectively).

The 12-month ADHD prevalence in this sample was 5.9\%. Analysis of comorbidity patterns showed that children with nocturnal enuresis had 2.6 times increased odds (95\% CI 1.0-6.9) of having full-syndrome ADHD compared with those without nocturnal enuresis, after adjustment for sex and age. There was no association between subthreshold ADHD and nocturnal enuresis. The 12-month prevalence of ODD was 4.9\%; there was no association between nocturnal enuresis and full-syndrome, subthreshold, or any ODD. The 12-month $\mathrm{CD}$ prevalence was $0.4 \%$. Nocturnal enuresis was significantly associated with subthreshold CD (OR 8.6, 95\% CI 1.744.8) (Table 2). We also examined associations between encopresis and DBD, but the numbers were too small for me- 
Table 1. Twelve-month prevalence of elimination disorder

\begin{tabular}{|c|c|c|c|c|c|c|}
\hline & \multicolumn{2}{|c|}{ Enuresis $(\mathrm{N}=29)$} & \multicolumn{2}{|c|}{ Encopresis $(\mathrm{N}=10)$} & \multicolumn{2}{|c|}{ Elimination disorder $(\mathrm{N}=37)^{\dagger}$} \\
\hline & $\mathrm{N}(\%)$ & $\mathrm{AOR}^{*}(95 \% \mathrm{CI})$ & $\mathrm{N}(\%)$ & $\mathrm{AOR}^{*}(95 \% \mathrm{CI})$ & $\mathrm{N}(\%)$ & $\mathrm{AOR}^{*}(95 \% \mathrm{CI})$ \\
\hline \multicolumn{7}{|l|}{ Sex } \\
\hline Male $(\mathrm{N}=834)$ & $21(2.9)$ & $2.4(1.0-5.5)$ & $9(1.2)$ & $8.2(1.0-65.0)$ & $28(3.9)$ & $2.9(1.3-6.2)$ \\
\hline Female $(\mathrm{N}=811)$ & $8(1.2)$ & Ref & $1(0.2)$ & Ref & $9(1.4)$ & Ref \\
\hline \multicolumn{7}{|l|}{ Age, years } \\
\hline $6(\mathrm{~N}=6)$ & $2(2.3)$ & $9.4(0.8-105.4)$ & $0(0.0)$ & - & $2(2.3)$ & $4.5(0.6-32.7)$ \\
\hline $7(\mathrm{~N}=339)$ & $11(3.2)$ & $12.2(1.6-100.2)$ & $4(1.2)$ & $4.0(0.4-36.3)$ & $14(4.1)$ & $8.0(1.8-35.6)$ \\
\hline $8(\mathrm{~N}=285)$ & $5(1.8)$ & $6.9(0.8-9.7)$ & $3(1.1)$ & $4.0(0.4-38.5)$ & $8(2.8)$ & $5.5(1.2-26.3)$ \\
\hline $9(\mathrm{~N}=273)$ & $8(3.2)$ & $11.2(1.4-90.8)$ & $2(0.7)$ & $2.3(0.2-25.3)$ & $9(3.3)$ & $6.1(1.3-28.6)$ \\
\hline $10(\mathrm{~N}=286)$ & $2(0.7)$ & $2.7(0.2-30.2)$ & $0(0.0)$ & - & $2(0.7)$ & $1.3(0.2-9.2)$ \\
\hline $11-12(\mathrm{~N}=377)$ & $1(0.3)$ & Ref & $1(0.3)$ & Ref & $2(0.5)$ & Ref \\
\hline \multicolumn{7}{|l|}{ Family income } \\
\hline$<200(\mathrm{~N}=233)$ & $6(2.6)$ & $1.7(0.7-4.4)$ & $0(0)$ & - & $6(2.6)$ & $1.3(0.6-3.1)$ \\
\hline$\geq 200(\mathrm{~N}=1105)$ & $13(1.2)$ & Ref & $9(0.8)$ & Ref & $20(1.8)$ & Ref \\
\hline
\end{tabular}

*AOR (95\% CI): adjusted odds ratio and 95\% confidence interval from model controlling for age, sex, and family income, ${ }^{\dagger}$ two children had both enuresis and encopresis

Table 2. Association between elimination disorder and disruptive-behavior disorder

\begin{tabular}{|c|c|c|c|c|}
\hline & Enuresis $(\mathrm{N}=29)$ & Non-enuresis $(\mathrm{N}=1616)$ & & \\
\hline & $\mathrm{N}(\%)$ & $\mathrm{N}(\%)$ & אט & $\mathrm{p}$ \\
\hline Full syndrome ADHD $(\mathrm{N}=97)$ & $6(20.7)$ & $91(5.6)$ & $2.6(1.0-6.9)$ & 0.049 \\
\hline Subthreshold ADHD $(\mathrm{N}=148)$ & $2(6.9)$ & $146(9.0)$ & $0.6(0.1-2.4)$ & 0.432 \\
\hline Any ADHD $(\mathrm{N}=245)$ & $8(27.6)$ & $237(14.7)$ & $1.4(0.6-3.4)$ & 0.400 \\
\hline Full syndrome ODD $(\mathrm{N}=81)$ & $2(6.9)$ & $79(4.9)$ & $1.0(0.2-4.4)$ & 0.985 \\
\hline Subthreshold ODD $(\mathrm{N}=126)$ & $1(2.7)$ & $125(7.8)$ & $0.3(0.04-2.4)$ & 0.270 \\
\hline Any ODD (N=207) & $3(10.3)$ & $204(12.6)$ & $0.6(0.2-1.9)$ & 0.366 \\
\hline Full syndrome $\mathrm{CD}(\mathrm{N}=7)$ & $0(0.0)$ & $7(0.4)$ & 0 & 0.998 \\
\hline Subthreshold CD $(\mathrm{N}=13)$ & $2(6.9)$ & $11(0.7)$ & $8.6(1.7-44.8)$ & 0.011 \\
\hline Any CD $(\mathrm{N}=20)$ & $2(10.0)$ & $18(1.1)$ & $4.7(1.0-22.4)$ & 0.050 \\
\hline
\end{tabular}

*AOR (95\% CI): adjusted odds ratio and 95\% confidence interval from model controlling for sex, age, and family income. ADHD: attention deficit/hyperactivity disorder, ODD: oppositional defiant disorder, CD: conduct disorder, AOR: adjusted odds ratio

aningful analysis.

\section{DISCUSSION}

This is the first nationally representative estimate of enuresis prevalence in an Asian country based on standardized diagnostic interviews. We found that $1.8 \%$ of Korean children ages 6 to 12 years in this sample have enuresis, and $0.6 \%$ of them have encopresis. In addition to replicating an association between enuresis and ADHD from previous studies, ${ }^{4,9,10,25-27}$ we showed an association between enuresis and CD symptoms, but no association between enuresis and ODD symptoms.

The established enuresis prevalence rate in this study (1.8\%) is much lower than that reported in previous two Korean stu- dies, which showed prevalence rates of $5.6 \%{ }^{24}$ and $9.4 \%{ }^{8}$ These discrepancies may be a result of differences between this study and previous studies in data collection methods and in the definition of nocturnal enuresis. We used structured clinical interviews and formal DSM-IV diagnostic criteria that required a bed-wetting frequency of twice per week for 3 consecutive months or the presence of clinically significant distress or impairment; previous studies used parent-rated questionnaires and much less stringent definitions (e.g, a bedwetting episode occuring at least monthly). When Lee et al. ${ }^{8}$ defined bed-wetting occuring at least weekly as nocturnal enuresis, the prevalence rates in their study decreased from $9.4 \%$ to $1.6 \%$, which is comparable to our findings.

Consistent with previous population-based studies, ${ }^{1,3,6,8-10,12,19}$ 
we found a higher prevalence of enuresis and encopresis in boys than in girls and maximum prevalence at age 7-9 years, followed by a decline by 12 years of age. Contrary to previous clinical studies, ${ }^{34}$ but consistent with previous epidemiological studies, ${ }^{10}$ socioeconomic status was not associated with enuresis in the current study.

The association between enuresis and ADHD confirms the findings of previous clinical studies ${ }^{25,26}$ and population-based studies ${ }^{4,9,10}$ in a large nationally representative sample. Previous research suggested that both enuresis and ADHD are related to delays in central nervous system maturation. ${ }^{5}$ Furthermore, a centrally located ADHD-inattentive dysfunction exerts a negative effect on arousability and brainstem signaling in enuresis. ${ }^{35,36}$ However, the results of a family study suggest that $\mathrm{ADHD}$ and enuresis are etiologically independent. ${ }^{37}$ Other researchers suggested that increased behavioral symptoms reflect coping behavior for dealing with the emotional and social burden of enuresis. ${ }^{9,29,38}$ Furthermore, parental attitudes about toilet training and discipline may be potential factors related to development of both enuresis and behavioral problems. ${ }^{9,39}$ We could not address the explantions for these association directly, but attempted to determine which hypothesis is most plausible through investigation of the association between enuresis and subthreshold ADHD, ODD, and $\mathrm{CD}$ as well as full syndrome ADHD.

Contrary to full-syndrome ADHD, ODD and subthreshold ADHD were not associated with nocturnal enuresis. These results suggest that high ADHD prevalence in children with nocturnal enuresis reflects a common neurobiological pathology rather than merely a coping response to enuresis-related psychosocial stress or common parenting factors because development of ODD and subthreshold ADHD is more affected by stress, conflict, and parenting than is development of clinical-level ADHD, which has a clear neurobiological pathologenesis. ${ }^{4041}$ In contrast to ODD, subthreshold CD and any $\mathrm{CD}$ were significantly associated with nocturnal enuresis, although analysis of full-syndrome $\mathrm{CD}$ was not possible due to the low number of $\mathrm{CD}$ children $(\mathrm{n}=7)$. $\mathrm{CD}$ is considered a more severe form of ODD, ${ }^{42}$ although many children with ODD do not go on to develop $\mathrm{CD},{ }^{43}$ and is reported to have a neurodevelopmental basis such as low cortisol level and abnormal neurocognitive function. ${ }^{44,45}$ In summary, a significant association of enuresis with $\mathrm{CD}$ and full syndrome $\mathrm{AD}$ $\mathrm{HD}$, along with the absence of any association with ODD or subthreshold ADHD, indicates that nocturnal enuresis is associated with more severe forms of DBD and may share a common neurobiological pathology with these disorders. However, it should be noted that there were no children with diurnal enuresis in this study; therefore association between diurnal enuresis and DBDs may differ from above findings. Previous studies indicated that children with daytime wetting or combined (day and night) wetting had a higher rate of parent-reported oppositional behavior as well as attention and conduct problems. ${ }^{30,31}$

There are several limitations of this study. First, the diagnosis of enuresis was not validated by medical evaluation. The diagnosis of DSM-IV enuresis requires exclusion of medical conditions that may contribute to bed wetting. As with most epidemiological studies, medical evaluation was not part of the diagnostic assessment in the current study. Second, the work was cross-sectional in design, making it impossible to identify a causal relationship between enuresis and DBDs. Third, there were only a small number of children with encopresis in our study population, and this reduced the statistical power to detect statistically significant demographic correlates or comorbidity of the disorder. Additionally, the number of children with full-syndrome $\mathrm{CD}$ was also too small for meaningful analysis, possibly because the mean age of the study population (8.95 \pm 1.71 years, age range: $6-12)$ was much lower than the average age of $\mathrm{CD}$ onset (10-12 years of age for boys and 14-16 years of age for girls). Finally, this study was done only in capital city, Seoul. Therefore, further longitudinal research in a national representative sample is needed.

Overall, nocturnal enuresis is a relatively common condition among children in Korea and is significantly associated with $\mathrm{ADHD}$ and $\mathrm{CD}$. Children with enuresis have more academic difficulty and externalizing problems compared with children without it. These findings suggest that children being assessed for enuresis should also be evaluated for the presence of $\mathrm{ADHD}$ and $\mathrm{CD}$ and other academic and behavioral difficulties.

\section{Acknowledgments}

This study was supported by Seoul Child and Adolescent Mental Health Center (Grant Number 07-2005-013-02) and by the Basic Science Research Program through the National Research Foundation of Korea (NRF) funded by the Ministry of Education, Science and Technology, Republic of Korea (Grant Number 013-2011-1-E00026).

\section{REFERENCES}

1. Bower WF, Moore KH, Shepherd RB, Adams RD. The epidemiology of childhood enuresis in Australia. Br J Urol 1996;78:602-606.

2. Byrd RS, Weitzman M, Lanphear NE, Auinger P. Bed-wetting in US children: epidemiology and related behavior problems. Pediatrics 1996; 98:414-419.

3. Chiozza ML, Bernardinelli L, Caione P, Del Gado R, Ferrara P, Giorgi $\mathrm{PL}$, et al. An Italian epidemiological multicentre study of nocturnal enuresis. Br J Urol 1998;81(Suppl 3):86-89.

4. Feehan M, McGee R, Stanton W, Silva PA. A 6 year follow-up of childhood enuresis: prevalence in adolescence and consequences for mental health. J Paediatr Child Health 1990;26:75-79.

5. Fergusson DM, Horwood LJ. Nocturnal enuresis and behavioral problems in adolescence: a 15-year longitudinal study. Pediatrics 1994;94: 662-668.

6. Hazza I, Tarawneh H. Primary nocturnal enuresis among school children in Jordan. Saudi J Kidney Dis Transpl 2002;13:478-480. 
7. Kajiwara M, Inoue K, Kato M, Usui A, Kurihara M, Usui T. Nocturnal enuresis and overactive bladder in children: an epidemiological study. Int J Urol 2006;13:36-41.

8. Lee SD, Sohn DW, Lee JZ, Park NC, Chung MK. An epidemiological study of enuresis in Korean children. BJU Int 2000;85:869-873.

9. Liu X, Sun Z, Uchiyama M, Li Y, Okawa M. Attaining nocturnal urinary control, nocturnal enuresis, and behavioral problems in Chinese children aged 6 through 16 years. J Am Acad Child Adolesc Psychiatry 2000;39:1557-1564.

10. Shreeram S, He JP, Kalaydjian A, Brothers S, Merikangas KR. Prevalence of enuresis and its association with attention-deficit/hyperactivity disorder among U.S. children: results from a nationally representative study. J Am Acad Child Adolesc Psychiatry 2009;48:35-41.

11. Spee-van der Wekke J, Hirasing RA, Meulmeester JF, Radder JJ. Childhood nocturnal enuresis in The Netherlands. Urology 1998;51:10221026.

12. Tai HL, Chang YJ, Chang SC, Chen GD, Chang CP, Chou MC. The epidemiology and factors associated with nocturnal enuresis and its severity in primary school children in Taiwan. Acta Paediatr 2007; 96:242-245.

13. Wang QW, Wen JG, Song DK, Su J, Zhu QH, Liu K, et al. Bed-wetting in Chinese children: epidemiology and predictive factors. Neurourol Urodyn 2007;26:512-517.

14. Yeung CK, Sreedhar B, Sihoe JD, Sit FK, Lau J. Differences in characteristics of nocturnal enuresis between children and adolescents: a critical appraisal from a large epidemiological study. BJU Int 2006;97: 1069-1073.

15. Srinath S, Girimaji SC, Gururaj G, Seshadri S, Subbakrishna DK, Bhola P, et al. Epidemiological study of child \& adolescent psychiatric disorders in urban \& rural areas of Bangalore, India. Indian J Med Res 2005; 122:67-79.

16. Costello EJ, Mustillo S, Erkanli A, Keeler G, Angold A. Prevalence and development of psychiatric disorders in childhood and adolescence. Arch Gen Psychiatry 2003;60:837-844.

17. Hansen A, Hansen B, Dahm TL. Urinary tract infection, day wetting and other voiding symptoms in seven- to eight-year-old Danish children. Acta Paediatr 1997;86:1345-1349.

18. Joinson C, Heron J, Butler U, von Gontard A, Avon Longitudinal Study of Parents and Children Study Team. Psychological differences between children with and without soiling problems. Pediatrics 2006;117:15751584.

19. van der Wal MF, Benninga MA, Hirasing RA. The prevalence of encopresis in a multicultural population. J Pediatr Gastroenterol Nutr 2005; $40: 345-348$.

20. World Health Organization. International Classification of Diseases and Related Health Problems (ICD-10) Classification of Mental and Behavioral Disorders: Diagnositc and Research Criteria. Geneva: World Health Organization; 1993.

21. Amerian Psychiatric Association. Diagnostic and Statistical Mannual of Mental Disorders. 3rd Edition. Washington DC: Amerian Psychiatric Association; 1980.

22. Amerian Psychiatric Association. Diagnostic and Statistical Mannual of Mental Disorders. 4th Edition. Washington, DC: Amerian Psychiatric Association; 1994.

23. Norgaard JP, van Gool JD, Hjalmas K, Djurhuus JC, Hellstrom AL. Standardization and definitions in lower urinary tract dysfunction in children. International Children's Continence Society. Br J Urol 1998; 81(Suppl 3):1-16.

24. Chung JM, Lee SD, Kang DI, Kwon DD, Kim KS, Kim SY, et al. An epidemiologic study of voiding and bowel habits in Korean children: a nationwide multicenter study. Urology 2010;76:215-219.

25. Baeyens D, Roeyers H, D’Haese L, Pieters F, Hoebeke P, Vande Walle J. The prevalence of ADHD in children with enuresis: comparison between a tertiary and non-tertiary care sample. Acta Paediatr 2006;
95:347-352.

26. Baeyens D, Roeyers H, Van Erdeghem S, Hoebeke P, Vande Walle J. The prevalence of attention deficit-hyperactivity disorder in children with nonmonosymptomatic nocturnal enuresis: a 4-year followup study. J Urol 2007;178 2616-2620.

27. Ghanizadeh A. Comorbidity of enuresis in children with attentiondeficit/hyperactivity disorder. J Atten Disord 2010;13:464-467.

28. Jarvelin MR. Developmental history and neurological findings in enuretic children. Dev Med Child Neurol 1989;31:728-736.

29. Butler RJ. Annotation: night wetting in children: psychological aspects. J Child Psychol Psychiatry 1998;39:453-463.

30. Joinson C, Heron J, Emond A, Butler R. Psychological problems in children with bedwetting and combined (day and night) wetting: a UK population-based study. J Pediatr Psychol 2007;32:605-616.

31. Joinson C, Heron J, von Gontard A. Psychological problems in children with daytime wetting. Pediatrics 2006;118:1985-1993.

32. Cho SC, Kim BN, Kim JW, Kim HW, Choi HJ, Jung SW, et al. The reliability and validity of diagnostic interview schedule for children version IV-Korean version (DISC-IV). J Korean Acad Child Adolesc Psychiatry 2006;18:138-144.

33. Cho SC, Kim BN, Kim JW, Hwang JW, Shin MS, Yoo HJ, et al. The 2005 Seoul Child and Adolescent Mental Health Survey. Seoul: Seoul Child and Adolescent Mental Health Center; 2006.

34. Baeyens D, Roeyers H, Vande Walle J, Hoebeke P. Behavioural problems and attention-deficit hyperactivity disorder in children with enuresis: a literature review. Eur J Pediatr 2005;164:665-672.

35. Elia J, Takeda T, Deberardinis R, Burke J, Accardo J, Ambrosini PJ, et al. Nocturnal enuresis: a suggestive endophenotype marker for a subgroup of inattentive attention-deficit/hyperactivity disorder. J Pediatr 2009;155:239-244.

36. Baeyens W, Daelemans A, Leloup T, De Mey A. Study of changes in nasal morphology in children with complete unilateral cleft lip and palate after secondary bone grafting measured with image analysis. Scand J Plast Reconstr Surg Hand Surg 2006;40:345-351.

37. Bailey JN, Ornitz EM, Gehricke JG, Gabikian P, Russell AT, Smalley SL. Transmission of primary nocturnal enuresis and attention deficit hyperactivity disorder. Acta Paediatr 1999;88:1364-1368.

38. Hagglof B, Andren O, Bergstrom E, Marklund L, Wendelius M. Selfesteem in children with nocturnal enuresis and urinary incontinence: improvement of self-esteem after treatment. Eur Urol 1998;33(Suppl 3): 16-19.

39. De Bruyne E, Van Hoecke E, Van Gompel K, Verbeken S, Baeyens D, Hoebeke P, et al. Problem behavior, parental stress and enuresis. J Urol 2009;182(4 Suppl):2015-2020.

40. Connor DF, Steeber J, McBurnett K. A review of attention-deficit/hyperactivity disorder complicated by symptoms of oppositional defiant disorder or conduct disorder. J Dev Behav Pediatr 2010;31:427-440.

41. Lavigne JV, Gouze KR, Hopkins J, Bryant FB, Lebailly SA. A multi-domain model of risk factors for ODD symptoms in a community sample of 4-year-olds. J Abnorm Child Psychol 2012;40:741-757.

42. Loeber R, Lahey BB, Thomas C. Diagnostic conundrum of oppositional defiant disorder and conduct disorder. J Abnorm Psychol 1991;100: 379-390.

43. August GJ, Realmuto GM, Joyce T, Hektner JM. Persistence and desistance of oppositional defiant disorder in a community sample of children with ADHD. J Am Acad Child Adolesc Psychiatry 1999;38:12621270 .

44. Barnett R, Maruff P, Vance A. Neurocognitive function in attentiondeficit-hyperactivity disorder with and without comorbid disruptive behaviour disorders. Aust N Z J Psychiatry 2009;43:722-730.

45. Gao Y, Glenn AL, Schug RA, Yang Y, Raine A. The neurobiology of psychopathy: a neurodevelopmental perspective. Can J Psychiatry 2009; 54:813-823. 